\title{
Secondary diabetes due to phaeochromocytoma
}

\author{
Dr Ashish Patel, Foundation Year One Doctor \\ Dr Jayadave Shakher, Consultant Diabetologist and Endocrinologist \\ Birmingham Heartlands Hospital, Heart fo England NHS Trust, UK
}

\section{Case}

A 73 year-old Pakistani gentleman with known hypertension and type 2 diabetes mellitus initially presented to hospital with hypotension, epigastric pain and vomiting. An abdominal CT confirmed no abdominal aortic aneurysm, but revealed an incidental finding of a $5.5 \times 3 \times 3.7 \mathrm{~cm}$ left-sided adrenal mass and a $1.5 \mathrm{~cm}$ gallbladder stone. He was treated for suspected cholecystitis and 24-hour urinary free catecholamines requested. Unfortunately he was lost to follow up.

He was admitted few years later with symptoms of vomiting and bilateral flank pain. On this occasion he was hypertensive (211/123). Urine dipstick was positive for leucocytes, protein and blood with his biochemistry mimicking an acute kidney injury pattern. Given the raised WCC (24.1) and renal angle tenderness, he was treated for pyelonephritis. A repeat CT abdomen confirmed the previous adrenal mass with no change in size. Repeat urinary free catecholamines were elevated. The urinary free adrenaline level was $1470 \mathrm{nmol} /$ coll (8-101) and noradrenaline level 748 $\mathrm{nmol} / \mathrm{coll}$ (82-650). Both noradrenaline and adrenaline creatinine ratios were also raised. An MIBG scan demonstrated increased uptake in the left adrenal mass. A diagnosis of phaeochromocytoma was confirmed.

Following adequate adrenergic block with phenoxybenzamine, he underwent an elective laparoscopic left-sided adrenalectomy. He recovered well post-operatively with his urinary catecholamines both within normal range. Histology confirmed the mass was a phaeochromocytoma. Following surgery both his blood pressure and capillary blood sugars normalised post-operatively and therefore no longer required insulin or anti-hypertensives.

\section{Discussion}

Phaeochromocytomas are commonly associated with impaired glucose tolerance through excessive production of catecholamines, hormonal antagonists of insulin. If a phaeochromocytoma is diagnosed and managed appropriately, it can lead to a significant reduction in the patient's insulin requirement and even resolution of their diabetes. Clinicians should maintain a high level of suspicion of secondary reversible causes when managing diabetic patients.

\section{References}

Wiesner TD, Blüher M, Windgassen M, Paschke $R$. Improvement of insulin sensitivity after adrenalectomy in patients with pheochromocytoma. J Clin Endocrinol Metab 2003;88:3632-3636

La Batide-Alanore A, Chatellier G, Plouin PF. Diabetes as a marker of pheochromocytoma in hypertensive patients. J Hypertens 2003;21:1703-1707

Stenström G, Sjöström L, Smith U. Diabetes mellitus in phaeochromocytoma, Fasting blood glucose levels before and after surgery in 60 patients with phaeochromocytoma. Acta Endocrinol (Copenh) 1984; 106:511-515

Rizza RA, Cryer PE, Haymond MW, Gerich JE. Adrenergic mechanisms for the effects of epinephrine on glucose production and clearance in man. J Clin Invest 1980;65:682-689

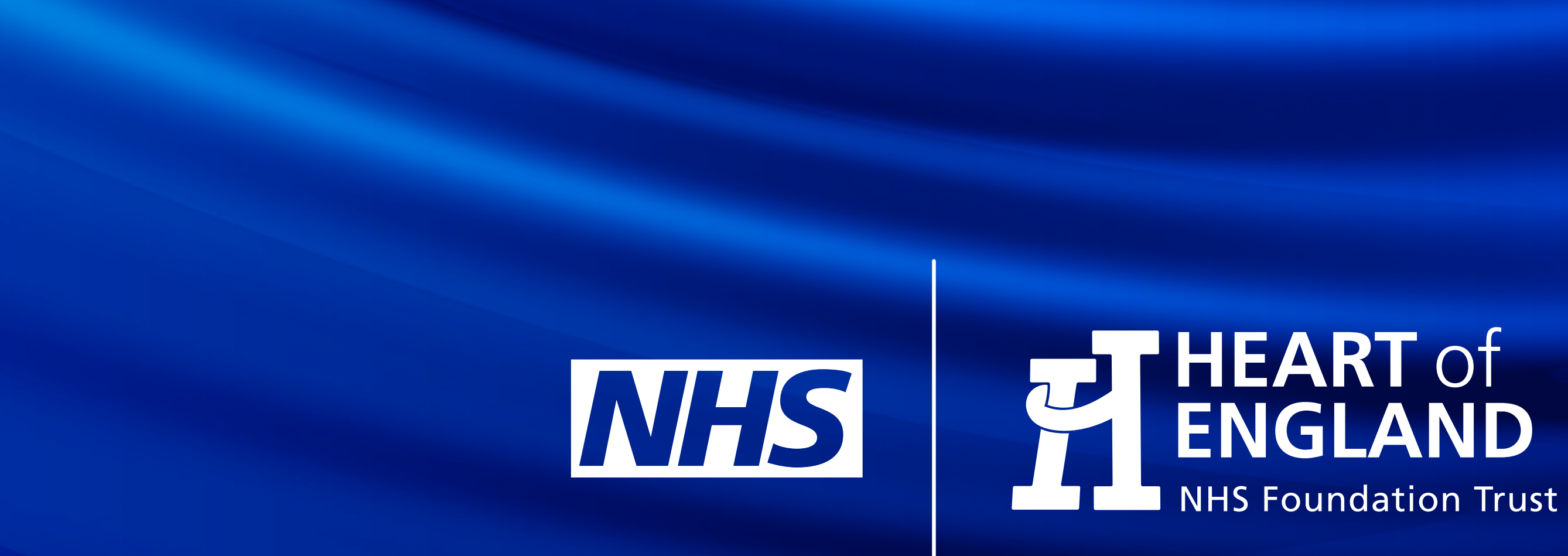

